\title{
Studies of children's probability learning behavior: VII. Effect of reward expectancy ${ }^{1}$
}

\section{STUART I. OFFENBACH, Purdue University, Lafayette, Ind. 47907}

Thirty-six third-grade children participated in a probability learning task under one of three presumed motivational levels. Rewarded children received toys for participating in the experiment. Children in a reward-expectancy group did not receive any toys in the experiment, but they did observe the rewarded children return to the classroom with toys. A control group did not receive or expect reward. The results indicated that the expectancy children were disappointed and withdrawn when they learned that they would not receive any toys. Performance differences were found in the children's response strategies but not in the overall probability learning behavior of the three groups.

Investigators of human behavior typically try to ensure that each S's behavior is free of knowledge of the experiment. Most of the time, this is accomplished by asking for, or enforcing in some manner, secrecy about the experimental procedure and the goals of the experiment. When Ss are adults, inter-S communication can be minimal since many of the participants are not known to each other. Inter-S communication is a more difficult problem to solve when the experimental $\mathrm{Ss}$ are children. In the primary or secondary school, when a child participates in an experiment, everybody in his class knows about it. The child gets up and leaves the classroom to go to the experimental session. When he returns, his behavior and attitude are noted almost immediately by his classmates. Such physical surroundings have led some investigators to ask the children to remain silent about the experiment. Other Es explain the purpose of the experiment, in general terms, to the class. When tangible rewards are available and the child returns with toys, candy, or money, the problem of inter-S communication is greater. The rest of the potential participants in the experiment suddenly are alert to the possibility that tangible, attractive rewards have something to do with the experiment. These children probably come to the experiment with a different motivational level or expectancies than the child who knows nothing about the reward contingencies. Just how this expectancy affects S's behavior has not been examined. The effects of reward delay (Renner, 1964) and delay of prefered rewards (Mishel, 1965) have been investigated, but there are no data concerned with complete and unexplained absence of expected reward.

In this study, a group of children who expected reward and did not receive it was compared with a group that received reward, and a group that did not expect, or receive reward. The probability learning task was used in this experiment because measures of overall performance and of response strategies both could be examined, and the effects of reward in probability learning have been examined. Typically, reward produces an increase in the number of predictions of the more frequent event [P( $\left.\mathrm{A}_{1}\right)$; Brackbill, Kappy, \& Starr, 1962; Offenbach, 1964; Siegel \& Andrews, 1962].

\section{SUBJECTS}

Thirty-six third-grade children participated in this experiment. All of the children were from the same rural school. There were 12 children in each of three experimental groups.

\section{PROCEDURE}

The children were tested in groups of four in a mobile laboratory parked adjacent to the school building. There were three conditions in the experiment. Children in the rewarded group (Group REW) chose two 10 toys as soon as they entered the experimental room. The children in Group REW all were tested in one morning. Children in a reward-expectancy condition (Group EXP) were tested in the afternoon after having

Table 1

Probability of $A_{1}$ Responses in Each Block of 20 Trials

\begin{tabular}{lcccccc} 
& \multicolumn{7}{c}{ Trials } \\
\cline { 2 - 7 } \multicolumn{1}{c}{ Group } & $1-20$ & $21-40$ & $41-60$ & $61-80$ & $81-100$ & $101-120$ \\
\hline Expectancy & .508 & .608 & .612 & .650 & .650 & .654 \\
Reward & .508 & .617 & .617 & .662 & .646 & .658 \\
Control & .521 & .512 & .571 & .575 & .637 & .617 \\
\hline
\end{tabular}

Table 2

Terminal Probabilities Associated with Several Response Strategies

\begin{tabular}{lcccrc}
\hline \multicolumn{1}{c}{ Source } & \multicolumn{5}{c}{ Condition } \\
\cline { 2 - 5 } & Control & Reward & Expectancy & $\chi^{2}$ & $\mathrm{p}$ \\
\hline P (A 1) & .627 & .652 & .652 & $<1.00$ & N.S. \\
P (Alternation) & .477 & .508 & .550 & 5.14 & N.S. \\
P (Win-Stay) & .588 & .599 & .585 & $<1.00$ & N.S. \\
P (Lose-Shift) & .554 & .655 & .716 & 12.61 & $<.01$ \\
\hline
\end{tabular}

* All $\chi^{2}$ values are compared to the chi-square distribution with 2 df. 
terminal level of $P\left(A_{1}\right)$ was identical. The number of $A_{1}$ responses in each block of 20 trials (Table 1) was examined in a repeated measures analysis of variance. The $\mathbf{P}\left(\mathrm{A}_{1}\right)$ for Group EXP and Group REW was consistently higher than that of Group CONT. The Reward by Trials interaction was not statistically significant $(F=0.671, d f=10 / 165, p>.05)$. With the Group REW and the Group EXP data combined, the $F$ value increased, but not to a statistically significant level $(F=1.361, d f=5 / 170, p>.05)$. These measures of overall learning performance indicated that the combined Group REW and $\operatorname{EXP} P\left(A_{1}\right)$ were higher than the $P\left(A_{1}\right)$ for Group CONT. However, the differences again were not reliable.

The differences observed in $P\left(A_{1}\right)$ indicate that the children who only observed classmates return with toys performed in an experimental task like children who actually did receive rewards. These results were consistent with the results of classroom studies by Auble \& Mech (1953). Auble and Mech concluded that children, in the presence of positive reinforcement, mediated the reward effect, or were affected, in the same way as the children who actually received the reinforcement.

Inspection of the rank order of the intratask measures in Table 2 indicated that the major shift in the groups was with respect to a lose-shift response strategy. The differences between the strategy probabilities was tested using a chi-square analysis described by Tate \& Clelland (1957). The only significant $\chi^{2}$ value was associated with the lose-shift strategy. The children in the expectancy condition shifted responses more. They also were more variable throughout the probability learning task. Offenbach (1968) interpreted increases in response variability (as indicated by alternations) as reflecting a less effective use of the information available in the task. This also appeared to be the case here. Children who expected reward and failed to receive it did not pay close attention to the task. Thus they did not utilize all of the information available. Such an interpretation is consistent with the differences observed in the overt extratask behavior of the children.

The extratask behavior by the children in the three groups differed markedly. The Group CONT children were moderately active and talkative, but their behaviors did not interfere with the testing session. The Group REW children, on the other hand, were noisy, excited, and had to be told to quiet down several times during the experimental session. These children behaved as though they thoroughly enjoyed the game and the testing session.
Group EXP children were altogether different. They were noisy when they entered the lab and heard the instructions concerning the game. As the task started and nothing was mentioned about toys, the children looked confused and uncertain. They became very quiet and noncommunicative. Verbal behavior diminished sharply, and several of the children indicated a reluctance to continue with the experiment. The children later indicated that they were disappointed when they realized that they were not going to get any toys. These reactions indicated that the children were well aware of the unmentioned and unexplained change in the procedure of the experiment.

These results indicated that care must be taken in experimental tasks with tangible reward since most children would be aware, in some general way, of the reinforcement contingencies. If the children are given some trinket after the experimental session, their motivational state may be quite different, during the task, from that of a child who received reward immediately. If the children received the reward at the beginning of the experimental session or were informed of the reward contingencies immediately, response variability might be minimized. Thus another source of error variance could be reduced or eliminated. REFERENCES

AUBLE, D., \& MECH, E. V. Quantitative studies of verbal reinforcement in classroom situations: I. Differential reinforcement related to the frequency of error and correct responses. Journal of Psychology, 1953, 35, 307-312.

BRACKBILL, Y., KAPPY, M. S., \& STARR, R. H. Magnitude of reward and probability learning. Journal of Experimental Psychology, 1962, 63, 32-35.

MISHEL, W. Theory and research on the antecedents of self-imposed delay of reward. In B. A. Maher (Ed.), Progress in experimental personality research. Vol. 3. New York: Academic Press, 1966. Pp. 85-132.

OFFENBACH, S. I. Studies of children's probability learning behavior: I. Effect of reward and punishment at two age levels. Child Development, 1964, 35, 709-715.

OFFENBACH, S. I. Studies of children's probability learning behavior: VI. Effect of event sequences. Journal of Experimental Child Psychology, 1968, 6, 460-469.

RENNER, K. E. Delay of reinforcement: A historical review. Psychological Bulletin, 1964, 61, 341-361.

SIEGEL, S., \& ANDREWS, J. A. Magnitude of reinforcement and choice behavior in children. Journal of Experimental Psychology, 1962, $63,337-341$.

TATE, M. W., \& ClEllaND, R. C. Nonparametric and shortcut statistics. Danville: Interstate Press, 1957.

\section{NOTE}

1. This study was supported, in part, by a grant from the National Institute of Child Health and Human Development (HD-01639). The author would like to thank Mr. Roger Campbell, Principal of the Hillcrest Elementary School, Delphi, Indiana, for his cooperation in providing children to serve as Ss in this study.

\section{Dual process of serial learning}

\author{
ROBERT M. SCHWARTZ, University of \\ British Columbia, Vancouver 8, B.C., \\ Canada
}

Using a combination of traditional chaining and position paradigms, a dual process of serial learning was tested. The design included a transfer from a serial to a paired-associate task in which both chaining and position cues were available. The results suggest that a dual process exists in serial learning, but no attempt was made to determine the exact nature of that dual process.

The effective stimulus in serial learning has traditionally been tested by two paradigms. The most common paradigm testing a chaining hypothesis involves transfer from a serial list to a double-function paired-associate list (e.g., Young, 1961, 1962) in which the stimulus-response pairs are composed of successive couplets taken from the serial list. Use of this paradigm generally finds 